\title{
Work in Progress: Exploring 'Ways of Thinking' of Interdisciplinary Collab- orators
}

\section{Dr. Medha Dalal, Arizona State University}

Medha Dalal has a Ph.D. in Learning, Literacies and Technologies from the Arizona State University with a focus on engineering education. She has a master's degree in Computer Science and a bachelor's in Electrical Engineering. Medha has many years of experience teaching and developing curricula in computer science, engineering, and education technology programs. She has worked as an instructional designer at the Engineering Research Center for Bio-mediated and Bio-inspired Geotechnics. Her research interests include interdisciplinary collaborations, ways of thinking, online/blended learning, and pedagogy of technology integration.

\section{Dr. Adam R. Carberry, Arizona State University}

Dr. Adam Carberry is an associate professor at Arizona State University in the Fulton Schools of Engineering Polytechnic School. He earned a B.S. in Materials Science Engineering from Alfred University, and received his M.S. and Ph.D., both from Tufts University, in Chemistry and Engineering Education respectively. His research investigates the development of new classroom innovations, assessment techniques, and identifying new ways to empirically understand how engineering students and educators learn. Prior to joining ASU he was a graduate student research assistant at the Tufts' Center for Engineering Education and Outreach. 


\title{
Work in Progress: Exploring 'Ways of Thinking' of Interdisciplinary Collaborators
}

\begin{abstract}
Calls have been made for novel ways of thinking about engineering education research. Building on an earlier qualitative inquiry, this work in progress study examined the number and nature of factors underlying the constructs of futures, values, systems, and strategic thinking within the context of interdisciplinary engineering education research. Exploratory factor analysis of survey data $(n=111)$ supported a correlated two factor structure for futures and strategic thinking, one factor for systems thinking, and a two to three factor structure for values thinking. The study has implications for researchers to better understand the multidimensional, correlated nature of various ways of thinking.
\end{abstract}

\section{Overview}

Many of the NSF calls for research look to foster innovation in the engineering education system through interdisciplinary collaborations between engineering and social sciences disciplines (NSF, 2017; Wankat, Felder, Smith, \& Oreovicz, 2002). Numerous activities associated with these collaborations are not well documented, including problem solving, ways of thinking, vision, values, and strategies to ensure a successful engineering education collaboration.

This work in progress study aims to explore these actions by assessing the ways of thinking used by engineering and social sciences researchers who come together for collaborative engineering education research (EER). The following sections describe the ways of thinking framework, instrument development, survey distribution processes, and initial exploratory factor analysis.

\section{Ways of Thinking}

The term ways of thinking is often associated with a systematic thought process (Sousa, 2016). This study operationalizes ways of thinking as a systematic thought process that informs decision-making to address complex educational challenges. It is not a heuristic, rather an approach used by collaborating researchers to think, act, and engage with their research. Different ways of thinking facilitate different strategies and subsequent actions to innovate. The study uses the Sustainability Education Framework for Teachers (Warren, Archambault, \& Foley, 2014) that embraces four ways of thinking including futures, values, systems, and strategic thinking to address complex educational challenges.

Futures thinking focuses on working to address tomorrow's problems today with anticipatory approaches to understand and prepare for future changes, problems, and solutions (Warren et al., 2014). Values thinking is about recognizing the concepts of ethics, equity, and social justice (Warren et al., 2014). It involves understanding these concepts in the context of varying cultures and accordingly making decisions. Systems thinking involves considering holistic approaches to problem-solving that understand and analyze the complexity of various elements and their interrelationships in the overall ecosystem (McKenna, Froyd, \& Litzinger, 2014). Strategic 
thinking is the ability to create a plan of action to achieve the desired vision and act upon the other ways of thinking (Warren et al., 2014).

Guided by this framework, the research question addressed by the study is:

What is the factor structure that captures futures, values, systems, and strategic thinking associated with interdisciplinary engineering education research?

\section{Research Methods}

\section{Instrument Development}

The survey instrument (see Appendix) was developed through iterative construction and validation over a three-month period. An initial draft of the instrument was prepared from the qualitative themes identified in a prior study (Dalal \& Carberry 2018; Dalal, Archambault, \& Carberry, 2019) using a mixed methods instrument development process of joint display (Creswell, 2015). Further refinement followed the scale development procedures recommended by DeVellis (2003). A five-point Likert scale ranging from "not at all important" to "extremely important" was used to measure importance of various activities associated with different ways of thinking, particularly in the context of participants' EER projects. A definition of the specific way of thinking was provided before the Likert-type questions to provide clarity. The instrument was validated through expert reviews and think aloud pilot sessions. Three experts (two engineering education researchers and one co-author of the SEFT framework) reviewed the instrument in its entirety. Edits were made on the initial draft based on their feedback. Next, think-aloud pilot sessions were conducted with four faculty members, two each from the engineering and social sciences disciplines. One engineering and one social sciences faculty had participated in the previous qualitative study (Dalal et al., 2019). Changes made based on the think-aloud sessions included simplifying the language of the systems thinking related items.

\section{Sample and Participants}

The potential survey participants were selected from among awardees listed in the public database on the NSF website (https://www.nsf.gov/awardsearch). The database search was limited to two specific programs within the Division of Engineering Education and Centers that stated a required collaboration with a social scientist. Listservs created within these programs were also used to reach other researchers who may not be listed on the NSF site.

A total population of 310 researchers resulted from these processes. Possible participants were removed due to a lack of available email information $(n=12)$. Five participants were also common across both programs. The final potential sample of 293 researchers were contacted with 130 responses received (44.4\% response rate). Multiple responses $(n=19)$ were removed following data collection because: 1) role on the project was an evaluator, administrator, or external consultant, or 2) less than $30 \%$ of the survey was complete. The final sample of 111 responses included $25 \%$ researchers from engineering disciplines, $18 \%$ from social sciences, $42 \%$ from both including engineering education, and $15 \%$ did not disclose their discipline. 


\section{Data Collection \& Analysis}

Over a five-week period in October and November, 2018 the survey was deployed using the Tailored Design Method (Dillman, Smyth, \& Christian, 2014) of web-based surveys for attaining higher response rates. A pre-notification was sent three days ahead of the survey link. Three reminders were sent once a week while the survey was open to increase the response rate. Amazon e-gift cards were also raffled off as an incentive. Raffle entries were collected using a separate link to maintain participant response anonymity.

Responses to the survey were analyzed using the Statistical Program for Social Sciences (SPSS) version 25. An exploratory factor analysis (EFA) using Promax rotation was conducted to elicit evidence of the underlying factor structure for the items under each way of thinking (Brown, 2015). The number of factors extracted were determined using parallel analysis with principal axis factoring (Crawford et al., 2010) and scree plot tests.

\section{Results}

\section{Futures thinking}

The means for each of the 10 items under futures thinking ranged from 2.56 to 4.15. The scree plot and parallel analysis both suggested two underlying factors. EFA confirmed the existence of two separate factors for futures thinking. All ten measures of futures thinking loaded independently on one of two factors with loadings ranging from 0.449 to 0.954 . Only factor loadings greater than 0.400 were considered (Costello \& Osborne, 2005). Factor 1 was conceptualized as preparation of future workforce and included items focused on student preparation, curriculum, and pedagogy. Rest of the items loaded on Factor 2 which was conceptualized as research practices. The futures thinking items under Factor 2 focused on lasting impact of research, imagining engineering education scenarios, continuous improvement, project continuation after funding, and translation of research to practice. The two factors were correlated at 0.60 with no significance.

\section{Values Thinking}

The means for nine items under values thinking ranged from 1.82 to 3.35. The Scree plot suggested two underlying factors, while parallel analysis suggested three factors. The threefactor model did not converge. On the two-factor solution, only six items loaded independently on one of two factors with loadings that ranged from 0.475 to 0.931 . Factor 1 was conceptualized as diversity values which included items related to valuing of diversity, heterogeneity, and inclusion in the profession. Three items related to the importance of alignment of personal values with either the research or with the collaborators loaded strongly on Factor 2, conceptualized as personal values. The two factors were correlated at 0.48 with no significance.

\section{Systems Thinking}

Total eight items under systems thinking focused on the recognition of different components, links, and cascading effects in the context of research projects as well as the larger engineering ecosystem. We had expected the items on the local project context to load separately from the items on the larger ecosystem. The item means ranged from 2.97 to 3.80. The Scree plot and 
parallel analysis indicated one underlying factor. EFA confirmed one factor which was conceptualized as sub-systems and interdependencies with factor loadings from 0.614 to 0.848 .

\section{Strategic Thinking}

The means for the nine items under strategic thinking ranged from 3.52 to 4.34, suggesting higher perceived importance of strategic thinking. The scree plot and parallel analysis both suggested two underlying factors. All items loaded independently upon one of the two factors with loadings in the range of 0.532 to 0.914 . Six items related to various strategies during different stages of research - from conceptualization to planning, implementation, evaluation, and dissemination - loaded strongly on Factor 1 which was conceptualized as research strategies. The remaining two items regarding collaboration strategies and personal growth strategies loaded strongly on Factor 2, conceptualized as personal strategies. The two factors correlated at 0.63 with no significance.

\section{Reliability}

Reliability of the items for each way of thinking and for the resulting factors was assessed using Cronbach's alpha. A value of 0.70 was used as a cutoff to indicate good reliability (Cronbach, 1951). The Cronbach's alpha values were $0.869,0.807,0.910$, and 0.885 for futures, values, systems, and strategic thinking respectively. Reliability coefficients for the factors were as follows: educating future workforce $(\alpha=0.776)$ and research practices $(\alpha=0.837)$ under futures thinking, diversity and inclusion $(\alpha=0.832)$ and personal values $(\alpha=0.728)$ under values thinking, sub-systems and interdependencies $(\alpha=0.876)$ under systems thinking, and research strategies $(\alpha=0.876)$ and personal strategies $(\alpha=0.861)$ under strategic thinking.

\section{Discussion}

This Work in Progress is a first step toward quantitatively examining futures, values, systems, and strategic thinking in the context of interdisciplinary collaborations between and among engineering and social sciences faculty. Preliminary findings suggest the nature of researchers' ways of thinking and provide guidance for future iterations of the instrument.

The two-factor EFA-model on futures thinking and strategic thinking yielded loading patterns without any cross-loadings. Further analysis should verify the correlated two factors under each construct as well as the relationships between and among the factors with a possibility of cross loadings. The findings for values thinking suggest a need for more data to verify the existence of three factors. We expected the items on diversity and inclusion to load together, but note that diversity and inclusion are two different concepts (Morely, 2018; Taylor, 2015). Future implementations of the instrument would still see them loading on the same factor, but the correlation value should decrease as awareness of the differences between diversity and inclusion increases. Items on systems thinking were designed to differentiate between the local project context and the larger engineering education ecosystem, but participants did not differentiate between the two. The identified one factor seems to capture the systems perspective from all levels. The items regrading local project context need further specificity. 


\section{Current and Future Work}

Current underway analysis includes an examination of broader EFA for all the items. We also plan to investigate differences in ways of thinking among various groups (e.g., experience or discipline). We intentionally refrained from collecting gender data from participants for this study, as we did not want participants to feel that their identities could be compromised or influenced their results. This was particularly important considering the survey targeted specific NSF awards with small populations. Future research will target a larger population that would allow us to examine gender influences for these four ways of thinking without previous hindrances. An immediate follow-up would be a refinement of survey items and scales through multiple iterations and a survey inquiry using confirmatory factor analysis to examine the rather intricate web of relationships between and among the ways of thinking for EER.

The need for innovation in engineering education necessitates research on ways of thinking. We sought to gain this understanding based on four specific ways of thinking including futures, values, systems, and strategic thinking. The study builds on the existing body of knowledge regarding these ways of thinking, while initiating a first step toward an 'EER ways of thinking' model. We believe the resulting model could serve as an organizing and motivating structure to frame decisions throughout all engineering education endeavors. 


\section{References}

Brown, T. A. (2015). Confirmatory factor analysis for applied research, 2nd edition. New York, NY: Guilford Publications

Crawford, A. V., Green, S. B., Levy, R., Lo, W. J., Scott, L., Svetina, D., \& Thompson, M. S. (2010). Evaluation of parallel analysis methods for determining the number of factors. Educational and Psychological Measurement, 70(6), 885-901.

Costello, A. B., \& Osborne, J. W. (2005). Best practices in exploratory factor analysis: Four recommendations for getting the most from your analysis. Practical Assessment, Research and Evaluation, 10(7), 1-9.

Creswell, J. W. (2015). A concise introduction to mixed methods research. Los Angeles, CA: Sage Publications.

Cronbach, L. J. (1951). Coefficient alpha and the internal structure of tests. Psychometrika, 16(3), 297-334.

Dalal, M., Archambault, L., \& Carberry, A. (2019). Exploring engineering and social sciences researchers' ways of thinking in the context of interdisciplinary collaborations. Unpublished manuscript.

Dalal, M. \& Carberry, A. (2018) Work in progress: 'Ways of Thinking' of interdisciplinary collaborators. Proceedings of the 2018 American Society for Engineering Education (ASEE) Annual Conference \& Exposition. Salt Lake City, UT.

DeVellis, R. F. (2003). Scale development: Theory and applications (Vol. 26) (2 $\left.{ }^{\text {nd }} \mathrm{Ed}\right)$. Thousand Oaks, CA: Sage publications.

Dillman, D. A., Smyth, J. D., \& Christian, L. M. (2014). Internet, phone, mail, and mixed-mode surveys: the tailored design method. 4th Ed. Hoboken, NJ: Wiley \& Sons

McKenna, A. F., Froyd, J., \& Litzinger, T. (2014). The complexities of transforming engineering higher education: Preparing for next steps. Journal of Engineering Education, 103(2), 188192. http://doi.org/10.1002/jee.20039

Morley, T. (2018). Making the business case for diversity and inclusion: Short case studies and research papers that demonstrate best practice in HR. Strategic HR Review, 17(1), 58-60.

National Science Foundation (2017). PFE: Research Initiation in Engineering Formation (PFE: RIEF) Retrieved from https://www.nsf.gov/pubs/2017/nsf17514/nsf17514.pdf

Sousa, D. A. (2016). How the brain learns $\left(5^{\text {th }} \mathrm{ed}\right)$. Singapore: Sage Publications Asia-Pacific Pte. Ltd.

Taylor, L. (2015). Report on the Missouri Diversity Summit. Journal of the Missouri Bar, 71, 238.

Wankat, P. C., Felder, R. M., Smith, K. A., \& Oreovicz, F. S. (2002). The scholarship of teaching and learning in engineering. In Huber and Morrealle (Eds), Disciplinary styles in the scholarship of teaching and learning: Exploring common ground (pp 217-238), Washington, D.C.: AAHE publications.

Warren, A., Archambault, L., \& Foley, R. W. (2014). Sustainability Education Framework for Teachers: Developing sustainability literacy through futures, values, systems, and strategic thinking. The Journal of Sustainability Education, 6(1), 1-14. 


\title{
Appendix
}

\author{
Ways of Thinking Survey
}

Q. 1 Futures thinking is about anticipatory approaches to understanding and preparing for future changes, problems, and solutions in the field of engineering education. It involves an understanding of how today's solutions could impact the field in the immediate, mid-range, and/or long term time frames.

a) In your engineering education research project, do you believe you have used futures thinking?

b) Please describe an example from your project that you believe involved futures thinking.

Q. 2 How important are/were the following actions considering futures in your research project? (Not at all important, somewhat important, moderately important, quite important, extremely important)

a) Engaging in scenario-building activities to imagine what engineering education might look like in the future

b) Preparing students to become future professionals

c) Preparing students to become contributing citizens of society

d) Changing curricula to include course(s) that are needed but not currently taught in the programs

e) Changing the teaching practices of engineering faculty through professional development

f) Selecting research projects that have a potential for long lasting impact

g) Adopting research practices to drive transformational change (e.g., examining the past, understanding trends, identifying problems, and developing focused questions)

h) Encouraging administrators to provide necessary infrastructure to support grant projects after external funding has expired

i) Focusing on ways to improve the translation of research to practice

j) Engaging in short-term thinking to impact the immediate future

Q. 3 Values thinking broadly involves one's philosophical, social, and cultural beliefs. It includes understanding the concepts of ethics, equity, and social justice in the context of different cultures, acknowledging varying perspectives, and making decisions accordingly.

a) In your engineering education research project, do you believe you have used values thinking?

b) Please describe an example from your project that you believe involved values thinking.

Q. 4 How important are/were following actions considering values (cultural, intellectual, social, monetary, etc.) in the context of your research project? (Not at all important, somewhat important, moderately important, quite important, extremely important)

a) Valuing diversity in the profession

b) Valuing inclusion in the profession

c) Reconciling personal values with those of your collaborator(s)

d) Aligning personal values with the engineering education research you pursue

e) Aligning societal values with the engineering education research you pursue

f) Improving engineering teaching for the purpose of addressing the needs of all students

g) Considering the heterogeneity of the end user(s) when creating a solution (e.g., differences in users' gender, ethnicity, age, experience, etc.)

h) Using research methodologies that highlight the value of context

i) Creating new knowledge through engineering education research

Q. 5 Systems thinking broadly involves considering holistic approaches to problem-solving. It is about understanding and/or analyzing the complexity of various components and subcomponents, as well as their interrelationships in the overall ecosystem.

a) In your engineering education research project, do you believe you have used systems thinking?

b) Please describe an example from your project that you believe involved systems thinking.

Q. 6 How important are/were the following actions considering the role of systems in your research project? (Not at all important, somewhat important, moderately important, quite important, extremely important)

a) Recognizing that a given problem may exist at different scales (local or global)

b) Integrating different aspects of the project to ensure synergy across all components 
c) Recognizing the implications of the project on all the stakeholders, even those not directly engaged as users, researchers, or collaborators

d) Recognizing the interdependence of components within the whole engineering education system (e.g., K-12 system, international partnerships, accreditation bodies, funding agencies, industry, professional bodies, etc.)

e) Uncovering interactions of elements within the engineering education system for a given problem

f) Thinking about implications of your research in the larger context of the engineering education ecosystem

g) Identifying cascading effects of a solution on other components within the engineering education system

h) Formulating problems considering the dynamic nature of the education system

Q. 7 Strategic thinking is the ability to create a plan of action to achieve the desired vision. It involves envisioning long term goals and objectives, collectively developing a plan, and considering appropriate courses of action and resource allocation that could lead to innovation in addressing today's challenges.

a) In your engineering education research project, do you believe you have used strategic thinking?

b) Please describe an example from your project that you believe involved strategic thinking

Q. 8 How important are/were the following actions considering strategies in the context of your research project?

(Not at all important, somewhat important, moderately important, quite important, extremely important)

a) Developing strategies to position your research within larger initiatives of your or your collaborator's organization

b) Employing strategies to convey the importance of your research to various audiences

c) Creating an overall plan for what is involved in the project

d) Developing strategic courses of action to execute the project

e) Using creative approaches to strategically address a challenging situation

f) Using evaluation strategies to capture the impact of your research

g) Improving strategies based on lessons learned at various stages of the project

h) Applying strategies that seek to strengthen your interdisciplinary collaboration

i) Developing strategies that contribute to your professional growth (e.g., diversifying for broader learning, relationship building, etc.)

Q. 9 Please select all the programs you are associated with at your institution from the choices below.

__Engineering __Education___Learning Sciences___Psychology __Engineering Education

Q. 10 For how many years have you been teaching in higher education?

Q. 11 For how many years have you been involved with interdisciplinary engineering education research?

Q. 12 Please select the job or title that best describes your current position at your institute.

__Professor __Associate professor __Assistant professor __Adjunct faculty _ Other

Q. 13 What is/was your role on the engineering education research project?

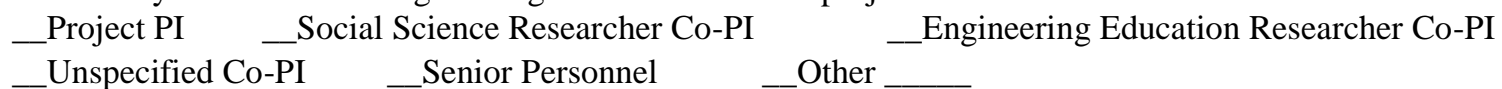

